\title{
Hybrid Braking System
}

\author{
Swapneel Linuskumar \\ Department of Mechanical Engineering, Dr. Jivraj Mehta Institute of Technology, Mogar, Gujarat, India \\ Devang Patel \\ Department of Mechanical Engineering, Dr. Jivraj Mehta Institute of Technology, Mogar, Gujarat, India \\ Vijesh Patel \\ Department of Mechanical Engineering, Dr. Jivraj Mehta Institute of Technology, Mogar, Gujarat, India \\ Rinkesh Patel \\ Department of Mechanical Engineering, Dr. Jivraj Mehta Institute of Technology, Mogar, Gujarat, India \\ Divyeshkumar Dave \\ Department of Mechanical Engineering, Parul Institute of Technology, Parul University, P.O.Limda, \\ Ta.Waghodia-391760, Vadodara, Gujarat(India),
}

\begin{abstract}
Hybrid braking system (HBS) is the braking system which reduced the automobile speed by detecting the speed limit sign, as well as it also applies brake when some other object is detect in front of vehicle. HBS system use sensors and camera around the vehicle to detect potential collisions and warn or even intervene in behalf of the driver to prevent or mitigate the collision. It is automatically activated with starting of vehicle. It can reduce accidents which are happened while human errors. HBS can reduce the braking distance compare to applied by human beings while it detected the object and take decision to apply brake. Hence it's quick response system. Keywords - Hybrid braking system, Sensor, Automobile
\end{abstract}

\section{INTRODUCTION}

Driving is an often activity for most people. People use their automobile vehicles to move from one place to another place or for transportation, numbers of vehicle and their technology are increase day by day, nowadays, accidents are increase and are uncertain. Accident will happens every time and everywhere and cause worst damage, serious injury and even death. These accidents are mostly cause by retard of the driver to push brake. This project is designed to develop a new technology system in which if the driver is fail to push brake the vehicle can stop automatically by detecting obstacles. As well as it is also detect the speed limit sign board which is provided on the roads and control the speed of the vehicle. By a report In India last year 1.46 lakh peoples where killed in road accidents. An increase of 5\% from 2014 the majority of road accidents victims are the 15-34 age group, by reporter it has been found that the cause of accident is by driver mainly because of over speeding the main states are Mumbai, Delhi, Tamil Nadu and Karnataka.so, by applying hybrid braking system in automobile. Below mention a graphical data which shows number of accidents in a year.

We can minimize the road accidents cause by new learners and drink and drive .In earlier similar type of projects are made by some inventors in which the speed of the vehicles are decrease by ultrasonic sensors, LIDAR sensor unit is used and that is successfully work. But in this project not only by ultrasonic sensors but also by the high speed cameras are also use to capture the speed limit boards so the driver can't accelerate above the limited speed, which can more perfectly detect the objects and can maximize the braking process.

The hybrid braking system is working on two different types of brake which is manual and automatic braking. Therefore it's called Hybrid Braking System. High speed camera is used for to capture the image speed limit board obstacles and ultrasonic sensor to detect the obstacles. In this the brake applied when the any vehicle are run more than speed limit or in front of vehicle any object will come then this brake will applied. The braking circuit's function is to stop the vehicle near to the obstacle to avoid collision. 


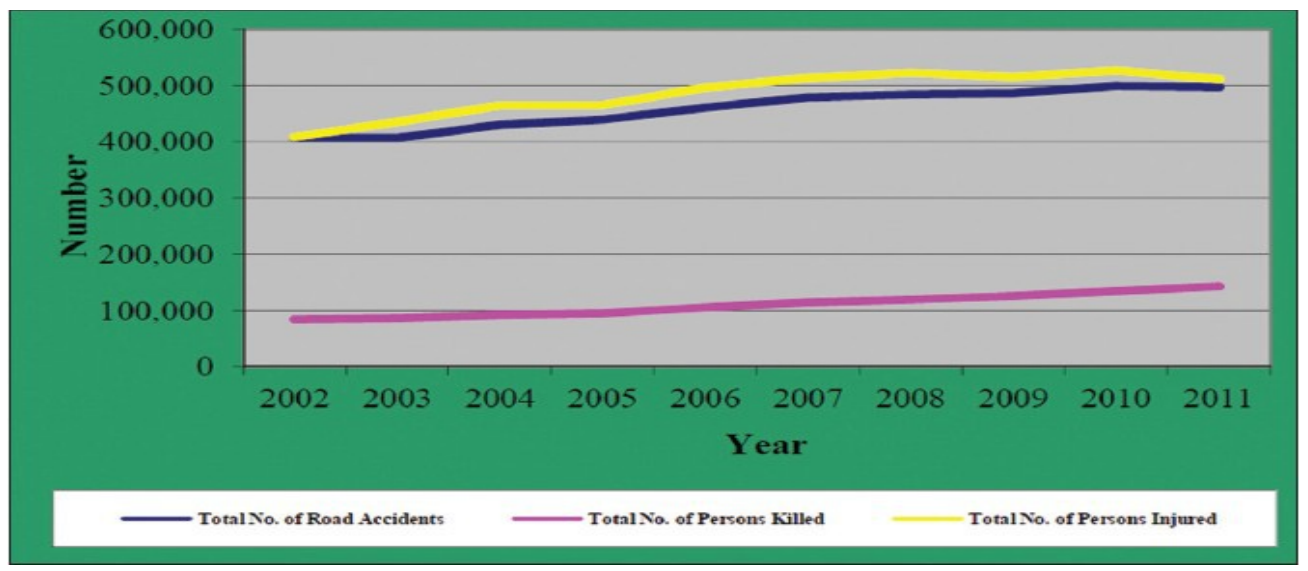

Figure 1: Numbers of accidents in India

\section{EXPERIMENT AND RESULT}

The working of hybrid braking system is following, the camera (required FPS 224 at 300kmph, working on $5 \mathrm{v}$ ) and sensors (distance range $500 \mathrm{~m}$, working on $5 \mathrm{v}$ ) for data input are established on the vehicle which are captured and detected the objects which are moving on the road and another objects as well as the road sign which are establishing on the road for the speed limits . Therefore, the data capturing and sensing by the camera and sensors is transferring to the motherboard using the wires. Data of camera is in digital mode and the sensors data is in analog mode. This data can input on motherboard (working on 9v). Motherboard is decoding this data from digital to analog in binary digits. This data also saved in the motherboard using external storage device. Motherboard has also their storage up to several limits.

The motherboard processes this data and compare with preprograming data. That preprogramming data is calculated by analysis and simulation of vehicle. After that comparison the motherboard take decision for the applying brake using programming data. The motherboard commands the relay to supply required amount power to applying brake related to particular condition. The relay (working on $5 \mathrm{v}$ ) has connected with the motherboard to get data from that [6]. It is connected with power source and motor in series connection. Using the data relay transmit required power to the motor to decrease speed. The motor get power from power source and rotation in forward or reverse direction. This can be applying brake pedal push or pull. The motor working on $12 \mathrm{v}$ and $2 \mathrm{amp}$. The motion of motor spindle which is transform rotational to reciprocating using rotary disc and shaft.

The shaft using here is adjustable because of different vehicles have different arrangement of brake pedals. The shaft is engage with the brake pedal to push or pull the brake pedal. Shaft has provided clearance at below for the manual brake. The working layout for the braking is as shown in fig 2. 


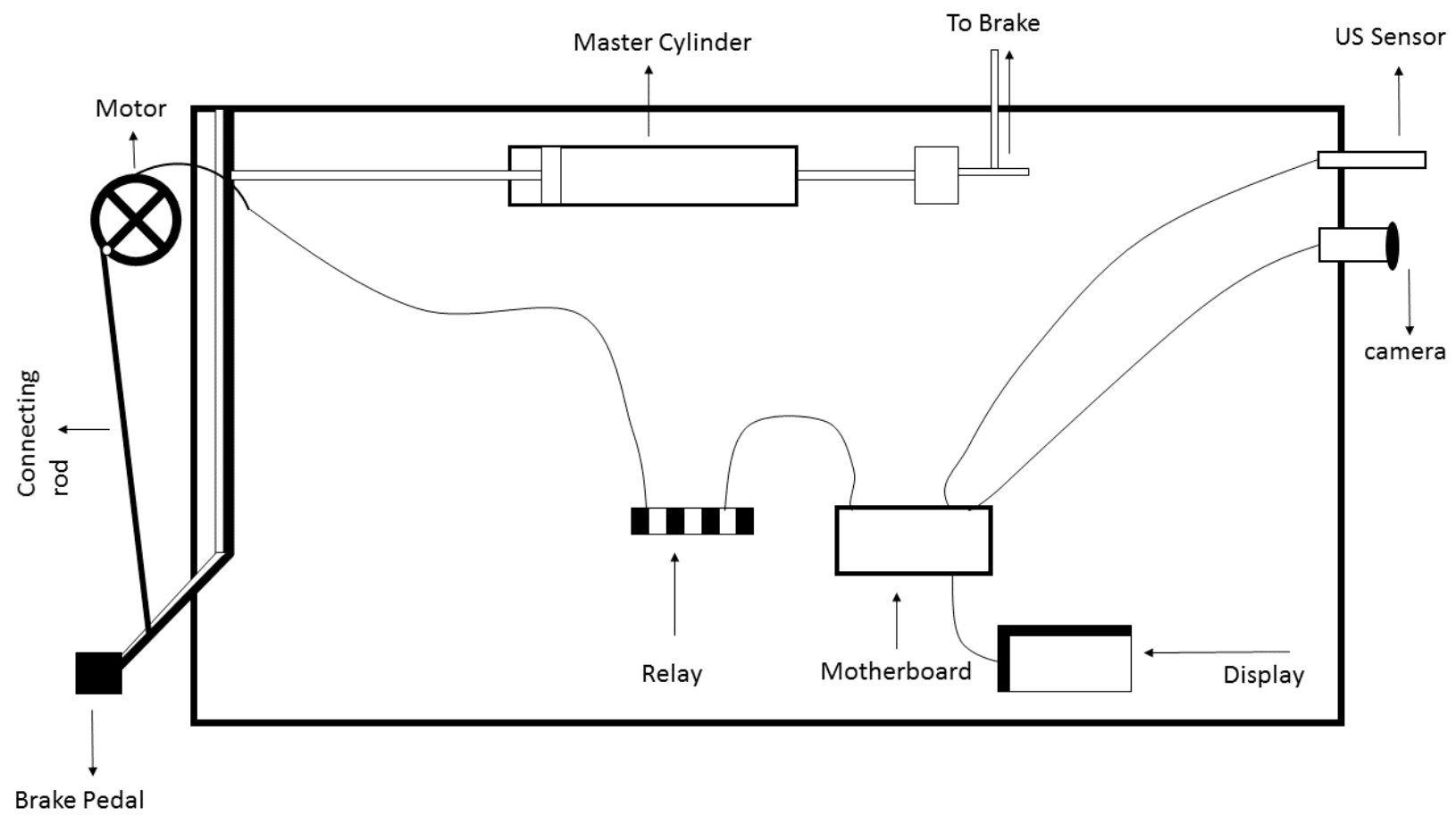

Figure 2 Work process layout

\section{Components}

Several components used in this system. These components are the major components for this system.

\section{Hydraulic Braking System}

In hydraulic braking system the hydraulic brake is a planning of braking mechanism which uses brake fluid .Generally containing ethylene glycol, to transfer pressure from the governing mechanism to the braking mechanism.

The function of the braking system is deceleration and absorption deceleration by stepping brake pedal, the brake pads compress the rotor attached to the wheel, which than force the vehicle to slow down due to friction. The brake absorbs the kinetic energy of the vehicle mechanically reduce the speed [10]. In mechanical, friction converts the kinetic energy into heat [9, 10]. While in electrical brakes, electrical current force to apply the brake [10].

The most common arrangement of hydraulic brake for automobile industry is Brake pedal, push rod, master cylinder assembly, piston assembly, reinforced hydraulic lines, Brake calliper assembly, Drum attached on axel etc..Hydraulic braking system is shown in figure 3[A].

\section{High Speed Camera}

A High speed camera is a device accomplished of image exposures in surplus of $1 / 1000$ or frame rates in excess of 250 frames per seconds. It is used for recording fast-moving object as photographic images onto a storage medium. $[4,5]$.Record image on many image planes or various locations on the same image plane. It is record with more FPS than the ordinary camera.

Required FPS for moving vehicle is calculated by:

$$
\mathrm{V}(\mathrm{m} / \mathrm{s}) * 3.285=\text { required FPS }[4]
$$


Use of high speed camera is to detect the other vehicles and mass and distance of the object in front of the vehicle. The image captured by the camera is transfer to motherboard. High speed camera shown in figure $3[\mathrm{~B}]$.

\section{Ultrasonic Sensor}

This sensor can be used to detect object in front of the vehicle at a range of $150 \mathrm{~mm}$ to $5 \mathrm{~m}$ with $10 \mathrm{~mm}$ resolution. The sensor is connected to the circuit board show above which control the timing of the pulses and calculate the perceived distance of object from the sensor. Ultrasonic sensor shown in figure $3[\mathrm{D}]$. .

\section{Motherboard}

Motherboard known as the main board, system board [7]. It is one of the main components of hybrid braking system. It is used to analyse the image captured by the camera show that the braking operation can be perform. Its old many crucial components of the computer including CPU, Memory and Connector. The function of motherboard is to get the image captured by the camera and an object detected by the sensor as an input and by coding and decoding convert that input message into a language that can be understand by the relay basis coding programming base controlling system performed by the motherboard which is pre-installed or also in commanding programming. [7] Motherboard shown in figure $3[\mathrm{C}]$.

Relay

A relay is an electrically operated switch. Relay is used an electro magnate in mechanically operate a switch. Relay is used to control a circuit by a separate low power signal or circuit control a by one signal .Relay shown in figure $3[\mathrm{E}]$. .

Motor

An electric motor is converts electrical energy into mechanical energy . In normal motoring mode most electric motor operate through the interface between an electric motors magnetic field and winding current to generate force within the motor. Electric motor can operate in both watering and generating or braking modes to also produce electric energy from mechanical energy [11]. General purpose of motor with highly standardized dimensions and characteristic provide convenient mechanical power for industrial used largest of electric motors are used for ship purpose propulsion, pipe line compression and pumped storage applications with rating within 100 megawatts. Electric motor may be categorized by electric power source type, internal structure, application and type of motion output and show on.

Electric motors are used to produced linier or rotary force and should be distinguished from devices such as magnetic solenoid and loud speakers that converts electricity into motion but do not generate usable mechanical power which are respectively referred to as actuators and transducers [11]. Display

A display device is an output device for a presentation of information in visual or tactile form [14]. When the input information is delivered as an electrical signal the display is called an electronic display. Common applications of electronic visual display are television or computer monitors some display can show only digits or alpha numeric characteristic. They are called segment display because they are composing of several segments that switch on and off to give appearance of desired glyph.

\section{Component Figures}




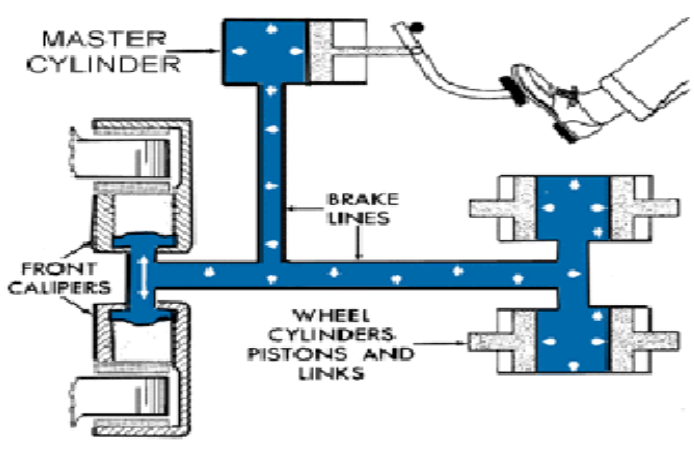

$[\mathrm{A}]$

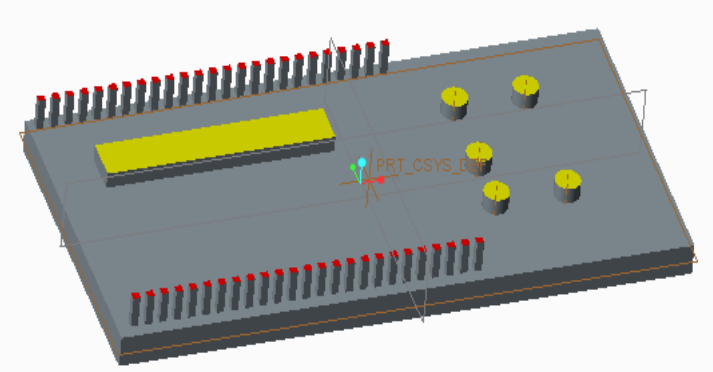

[C]

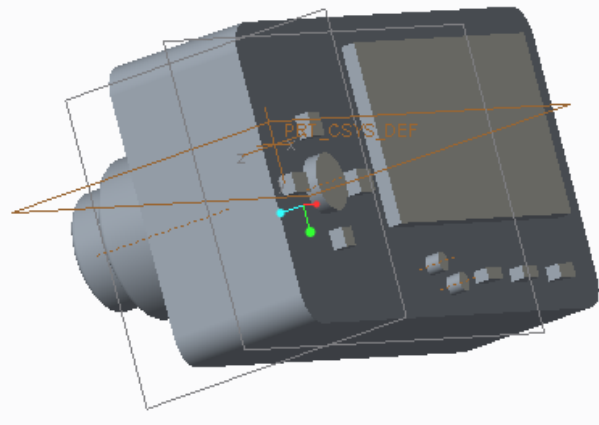

[B]

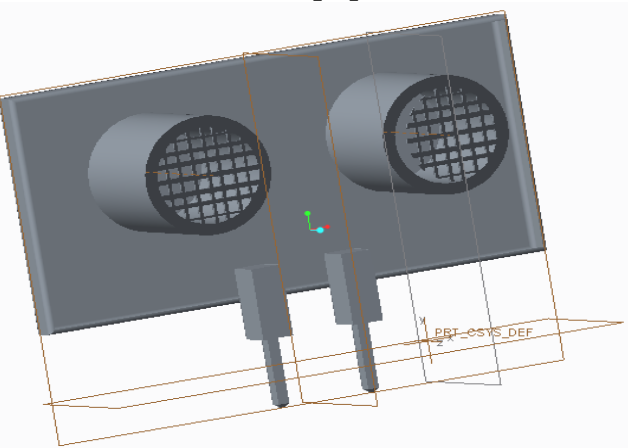

[D]

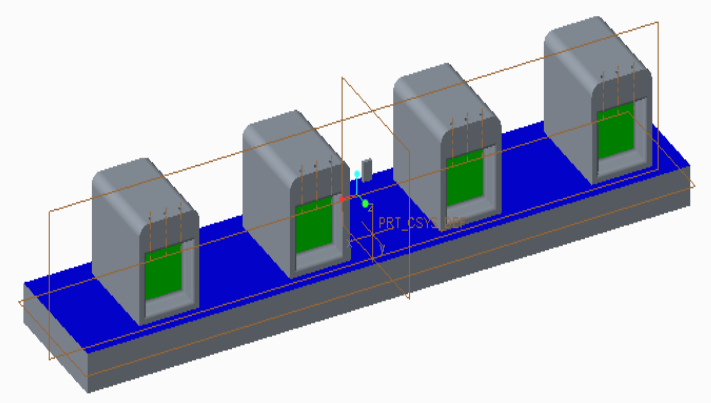

[E]

Figure 3: Hybrid braking system components

\section{Outcomes}

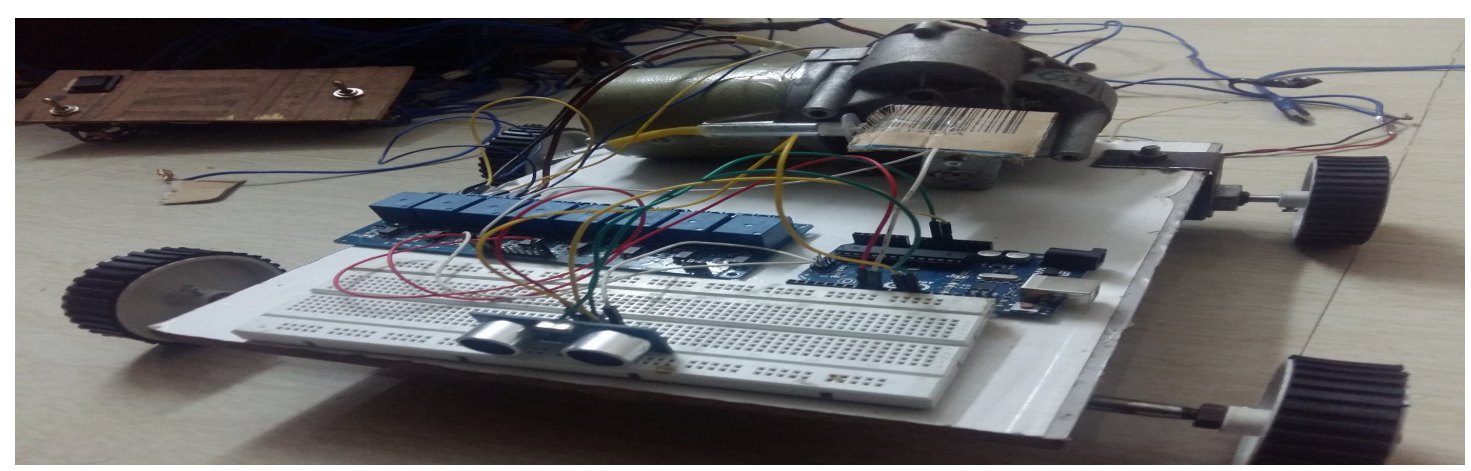

Here we have found desired outcome from our observation while testing and are as follows: 
1. The system is running completely correct as desired.

2. The object is detected from $5 \mathrm{~m}$ and its giving warning to user by display. The warning is shows with the remaining distance.

3. The brake is completely applied when object came near about $30 \mathrm{~cm}$. We observed that the braking distance compare to the manual brake is less and hence system is accurate and safe.

\section{III.CONCLUSION}

Braking system made with the using ultrasonic is more effective and useful. It is completely working with proper braking distance. According to selected sensor which was able to sense the obstruction up to $5 \mathrm{~m}$, it sensed properly and accordingly braking system worked smoothly. If in this system the high speed camera install then it will work more accurately according to the range of the same and braking system will work more effectively. Due to budgetary constrain unable to install in to this system.

\section{REFERENCE}

[1] S. Thorat, and J. U. A. S. D. SanketThorve, "Design and Implementation of Automatic Emergency Braking System," 2016.

[2] M. Avery, and A. Weekes, "Autonomous braking systems and their potential effect on whiplash injury reduction." pp. 1-7.

[3] M. Ruikar, "National statistics of road traffic accidents in India," Journal of Orthopedics, Traumatology and Rehabilitation, vol. 6 , no. 1 , pp. $1,2013$.

[4] B. Wilburn, N. Joshi, V. Vaish et al., "High-speed videography using a dense camera array." pp. II-294-II-301 Vol. 2.

[5] C. Pleasanton, "High Resolution, High-Speed Photography, an Increasingly Prominent Diagnostic in Ballistic Research Experiments," 1999.

[6] S. Bunting, and W. Wei, EnCase Computer Forensics: The Official EnCE: EnCaseÂ Certified Examiner Study Guide: John Wiley \& Sons, 2006.

[7] M. C. Ramon, "Intel galileo and intel galileo gen 2," Intel® Galileo and Intel® Galileo Gen 2, pp. 1-33: Springer, 2014.

[8] R. Mortimer, L. Segel, H. Dugoff et al., Brake force requirement study: driver-vehicle braking performance as a function of brake system design variables, 1970.

[9] V. A. Kumar, and S. Kalyan, “Active Safety Braking System," International Journal of Scientific and Research Publications, pp. 368.

[10] A. Shrivastava, A. Verma, and S. Singh, "Distance Measurement of an Object or Obstacleby Ultrasound Sensors using P89C51RD2," International Journal of Computer Theory and Engineering, vol. 2, no. 1, pp. 64, 2010.

[11] K. Beauvais, "The Simple DC motor: A Teacher's guide," Center for Material Science and Engineering, Massachusetts Institute of Technology, 2003.

[12] G. Pinski, and F. Narin, "Citation influence for journal aggregates of scientific publications: Theory, with application to the literature of physics," Information Processing \& Management, vol. 12, no. 5, pp. 297-312, 1976. 